Целью данной работы является создание программного продукта для обработки экспериментальных данных, а также моделирования теоретических измерений на атомном кластере, основываясь на эффектах многократного рассеяния электронов.

Проведен анализ экспериментальных и теоретических данных по фотоэлектронной дифракции и голографии с разрешением химических состояний элементов для систем $\mathrm{Bi}_{2} \mathrm{X}_{3}(\mathrm{X}: \mathrm{Se}, \mathrm{Te})$. Обсуждается возможность повысить чувствительность метода фотоэлектронной голографии к поверхностным слоям и точность этого метода за счет изменения энергии падающих фотонов, поляризации и селективного анализа угловой зависимости картины фотоэлектронной дифракции.

Работа выполнена при финансовой поддержке Российского фонда фундаментальных исследований (проект № 19-29-12061).

1. Dmitry Yu Usachov et al 2019 2D Mater. 6045046.

2. F. J. Garci'a de Abajo, M. A. Van Hove, C. S. Fadley. Multiple scattering of electrons in solids and molecules: A cluster-model approach. Phys. Rev. B. 63,075404. (2001)

\title{
ROLE OF THE MECHANICAL TREATMENTS IN THE FORMATION OF MAGNETOCALORIC PROPERTIES OF Gd MELT-SPUN RIBBONS
}

\author{
Arkhipov A.V. ${ }^{1}$, Andreev S.V. ${ }^{1}$, Neznakhin D.S. ${ }^{1}$, Tebenkov A.V. ${ }^{1}$, \\ Kurlyandskaya G.V. ${ }^{1}$, Svalov A.V. ${ }^{1}$ \\ 1) Ural Federal University, Yekaterinburg, Russia \\ E-mail: hemae2468@gmail.com
}

The magnetocaloric properties of deformed and milled Gd ribbons were carefully analyzed. The maximum of the temperature dependence of the magnetic entropy change value for the ribbon in the initial state, the powder sample and the deformed sample were 11.8, 3.2 and $1.9 \mathrm{~J} / \mathrm{kg} \cdot \mathrm{K}$ at $7 \mathrm{~T}$ respectively.

Energy efficiency challenge continues to attract close attention to the problem of magnetic cooling. Nevertheless, despite significant success in the development of new materials for magnetic refrigerators, gadolinium remains the most effective functional material operating near the room temperature [1]. The need for specific devices and applications requires different manufacturing methods and shapes of magnetic cooling elements. Nanocrystalline melt-spun ribbons are very suitable because they have a large surface (both sides are involved in the heat transfer), which contributes to the effective heat transportation and refrigeration while the mechanical properties allow their usage in flexible devices $[2,3]$. It is well known that the magnetocaloric effect (MCE) in rare-earth based materials depends on their structural state [4]. 
ФТИ-2020

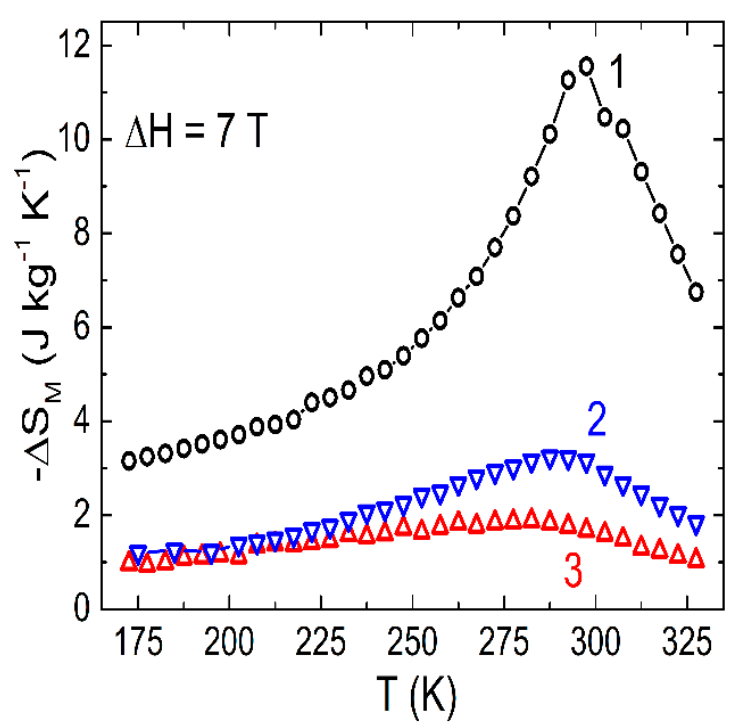

Fig. 1. Temperature dependence of magnetic entropy change $\left(-\Delta S_{M}\right)$ for sample of initial state ribbon(1), powder sample (2) and deformed sample (3)

In this work, we present a detailed study on magnetic and magnetocaloric properties of Gd ribbons after different kinds of mechanical treatments such as plastic deformation (value of pressure up to $11 \mathrm{GPa}$ ) and ball milling. The magnetic properties of the samples were measured by a SQUID magnetometer. The magnetic entropy change $\Delta \mathrm{S}_{\mathrm{M}}(\mathrm{T}, \mathrm{H})$ was quantified using the Maxwell relation follow the standard procedure.

It was found that the maximum value for the temperature dependence of the change of magnetic entropy $\Delta \mathrm{S}_{\mathrm{M}}$ for the ribbon in initial state was as high as $11.8 \mathrm{~J} / \mathrm{kg} \cdot \mathrm{K}$ at $\Delta \mathrm{H}=7 \mathrm{~T}$ (Fig. 1), i.e. very close to the corresponding value for the bulk gadolinium. The maximum values of the magnetic entropy change for the powder sample and the deformed sample in the same fields are substantially smaller (3.2 and 1.9 $\mathrm{J} / \mathrm{kg} \cdot \mathrm{K}$ respectively). The reason of a significant decay of the magnetic entropy change $\Delta \mathrm{S} \_\mathrm{M}$ in processed samples was carefully analyzed and discussed.

1. S. V. Taskaev, V. D. Buchelnikov, A. P. Pellenen et al. J. Appl. Phys. 113, 17A933 (2013)

2. V. Franco, J.S. Blázquez, J.J. Ipus, J.Y. Law, L.M. Moreno-Ramírez, A. Conde, Prog. Mater. Sci. 93, 112 (2018)

3. A. Svalov, S. Andreev, A. Arkhipov, E. Kudyukov, D. Neznakhin, A. Larrañaga, G. Kurlyandskaya, J. Phys.: Conf. Ser. 1389, 012100 (2019)

4. S. Taskaev, K. Skokov, D. Karpenkov, V. Khovaylo, M. Ulyanov, D. Bataev, A. Dyakonov, O. Gutfleisch, J. Magn. Magn. Mater. 479, 307 (2019) 